\title{
Sensitizing ROS1 Fusion Positive
}

National Cancer Institute

\section{Source}

National Cancer Institute. Sensitizing ROS1 Fusion Positive. NCI Thesaurus. Code C153502.

An indication that expression of ROS1 fusion containing a ROS1 alteration that causes increased sensitivity to ROS1 inhibitory agents has been detected in a sample. 